\title{
¿EXISTEN NODULOS COLOIDEOS TIROIDEOS QUE NO REQUIEREN PUNCION DIAGNOSTICA?
}

Drs. Eleonora Horvath(1), Sergio Majlis $D^{(1)}$, Carmen Franco ${ }^{(2)}$, Eduardo Soto $\mathbf{N}^{(1)}$, Juan P. Niedmann $E^{(1)}$.

1. Comité de Tiroides, Clínica Alemana de Santiago.

2. Instituto de Anatomía Patológica.

\section{ARE THERE ANY COLLOID THYROID NODULES WHICH DO NOT REQUIRE DIAGNOSTIC PUNCTURE?}

\begin{abstract}
Depending on age, sex, and geographic area, 19 to $67 \%$ of the general population is found to have thyroid nodules when submitted to ultrasonicaIly-guided diagnostic puncture. Being benign in more than a $80 \%$, most of them corresponds to colloid nodules. Indiscriminate fine-needle aspiration not only increases health costs but also generates anxiety in patients. The echographic-histological correlation of thyroid nodules made it possible to define five typical patterns (colloid patterns 1, 2, 3; neoplastic type, and malignant pattern). Thirty three percent of colloid nodules may appear as follicular neoplasms or malign nodules, being puncture the only means for recognizing and establishing the difference between them. Nevertheless, $67 \%$ of nodules presents a typical appearance that corresponds to colloid patterns 1, 2, and 3, which show a weak association to cancer risk (0\%, $0 \%$ and $1,5 \%$, respectively). On this basis, ultrasound follow-up is advised to recognize them in order to significantly diminish unnecessary diagnostic histological punctures.
\end{abstract}

Key words: Colloid nodule, Thyroid cancer, Thyroid ultrasound, US-guided fine-needle aspiration of the thyroid nodule.

Resumen: En el 19 al 67\% de la población general se diagnostican nódulos tiroideos mediante ultrasonografía, dependiendo de la edad, sexo y área geográfica. En más del $80 \%$ su naturaleza es benigna y la gran mayoría corresponde a nódulos coloideos. Su punción indiscriminada aumenta costos y genera ansiedad.

La correlación ultrasonográfica-histológica de los nódulos tiroideos permitió definir cinco patrones característicos (patrón coloideo típico tipos 1 a 3,

Horvath E, y cols. ¿Existen nódulos coloideos tiroideos que no requieren punción diagnóstica? Rev Chil Radiol 2008; 14: 5-10.

Correspondencia: Dra. Eleonora Horvath eleonora.horvath@gmail.com patrón neoplásico y patrón maligno). El 33\% de los nódulos coloideos simula la apariencia de nódulos de tipo neoplasia folicular o de aspecto maligno $y$, sólo con punción se puede diferenciar entre ellos. No obstante, el 67\% de los nódulos tiene aspecto típico y corresponden a patrones coloideos Tipo 1, 2 y 3, con una baja asociación con cáncer (0\%, 0\% y 1,5\% en los tres grupos respectivamente), lo que autoriza su seguimiento ultrasonográfico. Al reconocerlos como tal, se puede disminuir en forma significativa las punciones diagnósticas innecesarias.

Palabras clave: Cáncer tiroideo, Ecografía tiroidea, Nódulo coloideo, Punción eco-guiada de nódulo tiroideo con aguja fina.

\section{Introducción}

La patología nodular tiroidea es extremadamente frecuente y aumenta con la edad. En ultrasonografía (US) encontramos nódulos en el 19 al 67\% de la población general, dependiendo de la edad, sexo y área geográfica con suficiente o insuficiente yodo ${ }^{(1)}$. Más del $80 \%$ de ellos es benigno ${ }^{(2)}$ y los nódulos coloideos son lejos los más frecuentes. Su punción indiscriminada introduce un aumento significativo de los costos para los servicios de salud, generando además ansiedad y un estrés adicional para los pacientes.

\section{Objetivos}

Con el fin de disminuir las punciones diagnósticas innecesarias, diseñamos un estudio cuyos objetivos fueron: describir los patrones ultrasonográficos que permitan caracterizar los nódulos coloideos y definir aquellos con baja asociación de malignidad.

\section{Material y método}

Durante un período de 4 años (febrero 2003febrero 2007) se registraron en forma prospectiva las características ultrasonográficas de 1.188 nódulos tiroideos consecutivos puncionados en nuestra institución, en una base de datos (FileMaker Pro 8,5). De éstos, fueron seleccionados aquellos nódulos cuya punción diagnóstica concluyó en un nódulo coloideo, que correspondieron a 619, que constituyen el universo para el análisis propuesto. 
Las punciones aspirativas con aguja fina (PAAF) fueron realizadas con agujas de 19 y 21 Gauge con guía ultrasonográfica (ecógrafos ATL HDI5000 y Philips IU22, transductores de 5-12 y 5-17 MHz), por radiólogos o endocrinólogos apoyados por radiólogos, utilizando la técnica de coágulo(3), para estudio histológico.

Para clasificar los nódulos tiroideos se utilizó un estudio anterior no publicado, efectuado en nuestra institución en el período enero 2002-enero 2003, que incluyó 362 nódulos tiroideos evaluados ultrasonográficamente y puncionados en las mismas condiciones antes descritas, donde fueron definidos 5 patrones (coloideos tipo 1, 2, 3, patrón neoplásico y patrón maligno).

\section{Patrón coloideo Tipo 1 (Figura1)}

Lesión quística, anecogénica con spots hiperecogénicos. Generalmente mide entre 1 y $15 \mathrm{~mm}$ de diámetro y corresponde a un macrofolículo.

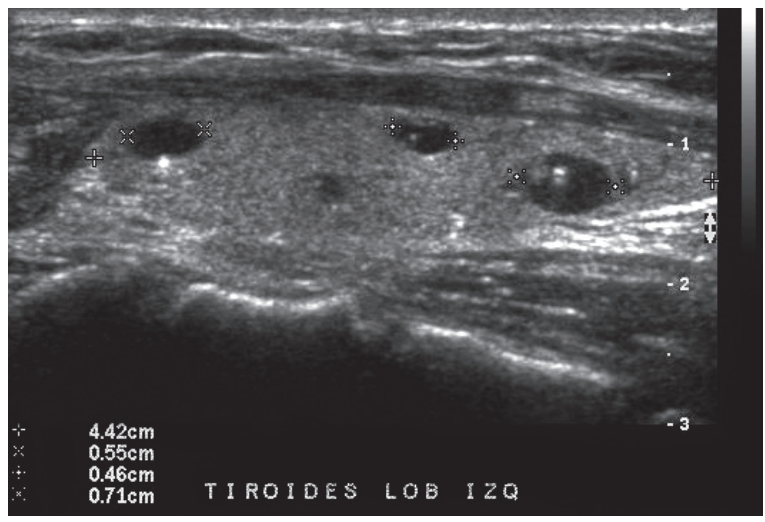

Figura 1. Patrón coloideo tipo 1: Imágenes anecogénicas con spot hiperecogénico que caracteriza el quiste coloideo.

\section{Patrón coloideo Tipo 2 (Figura 2)}

Nódulo mixto con aspecto de «rejilla», de forma oval, no expansivo que, pese a su tamaño, no deforma la glándula. No posee cápsula, contiene numerosos spots hiperecogénicos y es hipervascularizado.

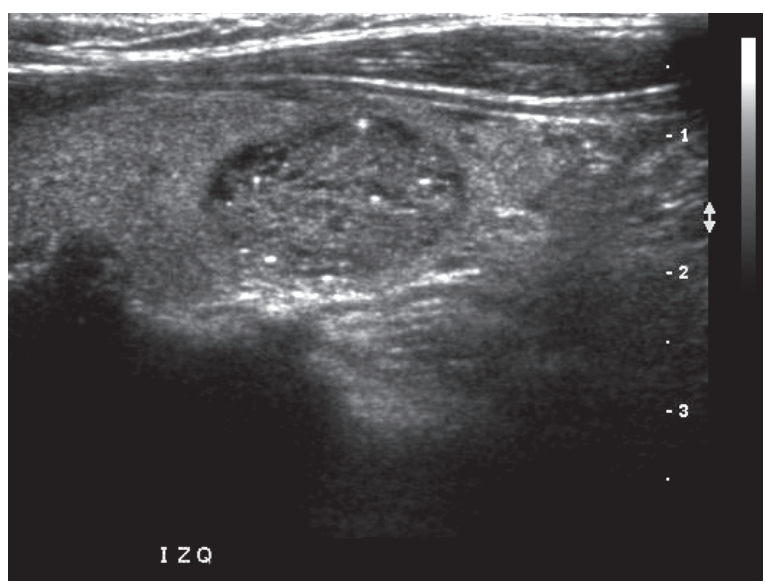

Figura 2. Patrón coloideo tipo 2: Nódulo isoecogénico mixto, con aspecto de «rejilla», sin cápsula, poco expansivo, con spots hiperecogénicos.

\section{Patrón coloideo Tipo 3 (Figura 3)}

Nódulo mixto, deforma la glándula, márgenes imprecisos, no posee cápsula o ésta es incompleta, porción sólida isoecogénica generalmente vascularizada al Doppler color. Frecuentes mamelones, tabiques gruesos y paredes engrosadas en forma irregular en las variantes principalmente quísticas.

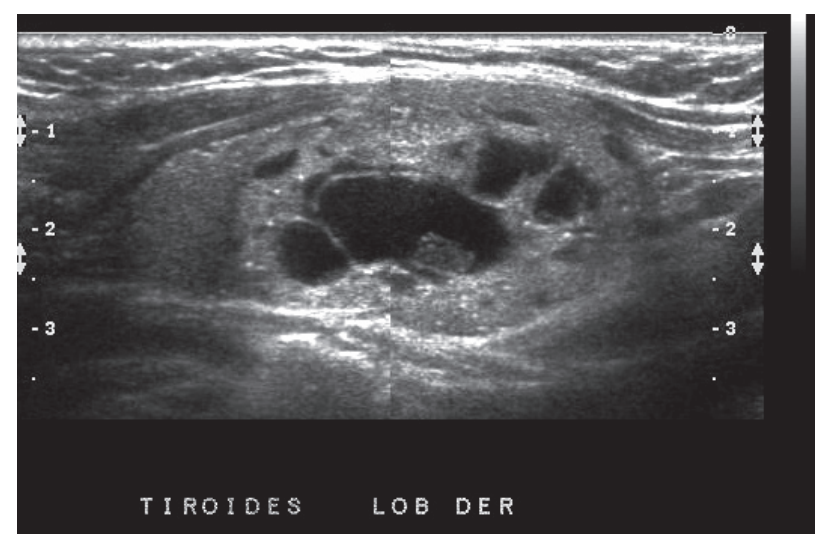

Figura 3. Patrón coloideo tipo 3: Nódulo mixto, isoecogénico, con componente quístico y tabiques, sin cápsula, con spots hiperecogénicos.

\section{Patrón de neoplasias foliculares (NF) (Figura 4)}

Nódulo sólido, a veces mixto, iso-hiper o hipoecogénico, siempre con cápsula, con o sin calcificaciones, con patrón de vascularización periférica y ramas intranodulares.

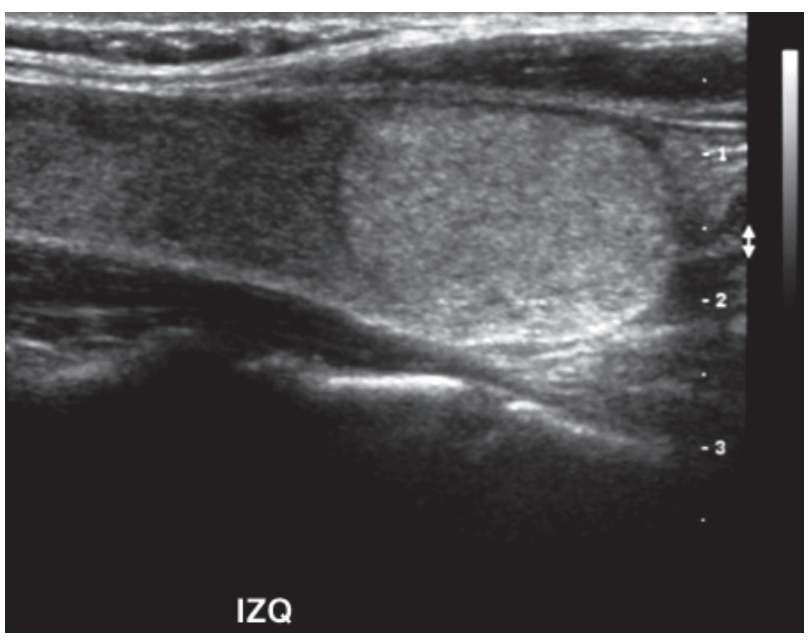

Figura 4. Patrón neoplásico: Nódulo sólido, de estructura interna homogénea, hiperecogénico, con cápsula.

\section{Patrón maligno (Figura 5)}

Lesión hipoecogénica, no encapsulada, de forma y márgenes irregulares, con o sin calcificaciones (gruesas o microcalcificaciones), generalmente vascularizada al Doppler color con vasos penetrantes. 


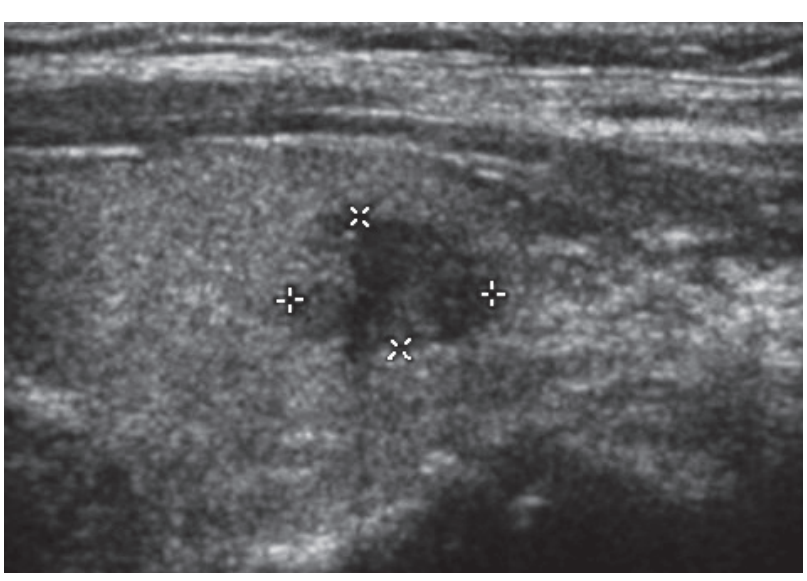

Figura 5. Patrón maligno: Nódulo sólido hipoecogénico, de márgenes irregulares, sin capsula.

Todos los nódulos puncionados y estudiados histológicamente $(n=1.188)$, fueron clasificados en uno de los 5 patrones ultrasonográficos de manera prospectiva, al momento del procedimiento. Según el resultado de la PAAF se determinó el porcentaje de malignidad en cada categoría. Se seleccionaron las lesiones cuya punción reveló "bocio coloideo", "nódulo coloideo" o "nódulo coloideo hiperplástico" y se analizó su distribución en los 5 patrones pre-definidos.

\section{Resultados}

Se diagnosticaron por punción 619 lesiones coloideas en 541 pacientes (462 mujeres y 79 hombres, de 16 a 82 años, con edad promedio de 52,3 años), que representan el $52 \%$ de la serie (Figura 6 ).

El tamaño de los nódulos coloideos osciló entre 5 y $65 \mathrm{~mm}$, con un promedio de $22 \mathrm{~mm}$.

La Tabla I muestra la distribución de los nódulos coloideos puncionados en los cinco patrones predefinidos: patrón coloideo tipo $1(0,8 \%)$ patrón coloideo tipo $2(1,6 \%)$, y patrón coloideo tipo $3(64,8 \%)$, patrón neoplásico $(27,3 \%)$, y patrón maligno $(5,5 \%)$.

En la serie total $(n=1.188)$, la incidencia de los cánceres fue $0 \%, 0 \%$ y $1,5 \%$ en los patrones tipo 1 , 2 y 3 respectivamente, $10,2 \%$ en el patrón neoplásico y $64,9 \%$ en el patrón maligno (Tabla II).

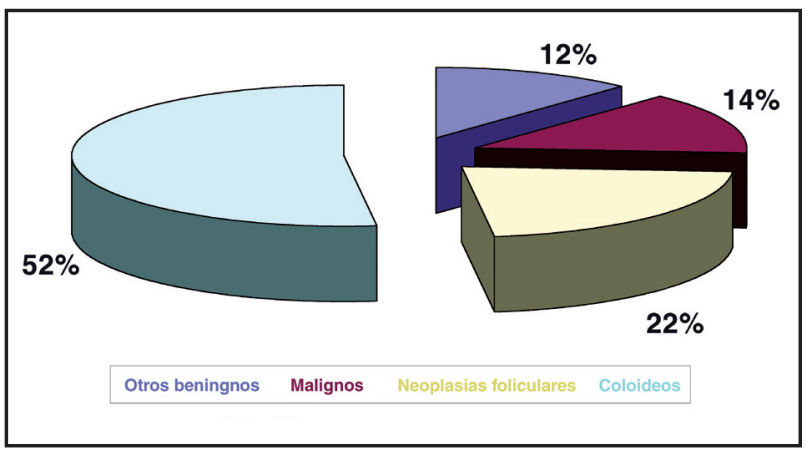

Figura 6. Resultado histológico de 1.188 nódulos puncionados. Relación PAAF benigno / no benigno=1,7:1.
Tabla I. Distribución en los 5 patrones ecográficos predefinidos de las 619 lesiones que resultaron nódulos coloideos en la PAAF.

Patrones pre-definidos Número de nódulos \%

\begin{tabular}{|lrr|}
\hline Patrón coloideo Tipo 1 & 5 & 0,8 \\
Patrón coloideo Tipo 2 & 10 & 1,6 \\
Patrón coloideo Tipo 3 & 401 & 64,8 \\
Patrón neoplásico & 169 & 27,3 \\
Patrón maligno & 34 & 5,5 \\
Total & 619 & 100,0 \\
\hline
\end{tabular}

\section{Discusión}

Actualmente, la PAAF es considerada como el mejor examen para el diagnóstico y manejo del nódulo tiroideo. Con el material aspirado, se preparan 2 a 4 frotis que se fijan de inmediato con laca o alcohol y posteriormente se tiñen con Papanicolau para examen citológico. En la literatura, las punciones tiroideas sólo pretenden conseguir material para estudio citológico. En las grandes series a nivel internacional, el promedio de muestras insatisfactorias para diagnóstico está sobre un $16 \%$ (6,4-32\%), estrechamente relacionado con las características del nódulo y la experiencia del equipo médico(4).

Cabe destacar que la "técnica del coágulo", técnica chilena poco conocida en el mundo y publicada hace más de 10 años en la Revista Médica de Chile, permite conseguir tanto frotis para estudio citológico, como coágulos (al traumatizar el nódulo con la aguja) para estudio histológico ${ }^{(3)}$. El coágulo se fija en formalina tamponada al $10 \%$ y posteriormente se procesa como cualquier biopsia estándar. El estudio histológico no influye en la especificidad y sin embargo mejora la sensibilidad del método. En la serie publicada del Hospital San Juan de Dios, la sensibilidad de la citología y del examen histológico del coágulo fue de $68.5 \%$ y $87.8 \%$, respectivamente $(p<0.035)^{(3)}$.

En nuestra experiencia, gracias al uso exclusivo de la técnica de coágulo, la tasa de muestras insuficientes es muy baja $(57 / 1.188=4.8 \%)$ para la primera punción. La mayoría de los nódulos se beneficia con una segunda punción que resulta diagnóstica en el $78 \%$ de los $\operatorname{casos}^{(5)}$.

En el examen microscópico de la pieza operatoria, los nódulos coloideos hiperplásticos aparecen como nódulos no encapsulados, constituidos por macrofolículos repletos de coloide, revestidos por epitelio aplanado, con núcleos de tamaño uniforme (Figura 7). Los nódulos pueden ser parcial o completamente microfoliculares, por lo que el diagnóstico diferencial con una neoplasia folicular es muy difícil, especialmente en una muestra por punción. Sin embargo, las células son cuboides o cilíndricas con núcleos pequeños y homogéneos a diferencia de las neoplasias, en las 
que generalmente hay núcleos de diversos tamaños y con atipias. En las zonas quísticas, se pueden observar pseudopapilas e incluso papilas verdaderas pero sin las características nucleares del carcinoma papilar. Generalmente hay evidencia de hemorragia antigua (macrófagos cargados con hemosiderina) y áreas de hemorragia reciente. En zonas de necrosis isquémica se ven abundantes macrófagos espumosos. Los nódulos antiguos presentan tabiques fibrosos con áreas calcificadas e incluso osificación.

Los nódulos coloideos tienen en común la presencia de material coloide (un concentrado de tiroglobulina, PAS-positivo). En US, el coloide se reconoce como un área anecogénica y en su interior, generalmente adosada a la pared o tabiques, se visualizan imágenes hiperecogénicas puntiformes con artefacto en "cola de cometa"(6). Estos spots hiperecogénicos corresponderían a detritus de cristales (Figura 7) oxalato de calcio $y / 0$ de colesterol ${ }^{(7)}$. No se los debe confundir con las microcalcificaciones de los cánceres tiroideos, que generalmente corresponden a cuerpos de psammoma. A diferencia de los spots hiperecogénicos observados en el material coloide, éstas se encuentran en tejido sólido, hipo y/o isoecogénico (Figura 8 a y b).

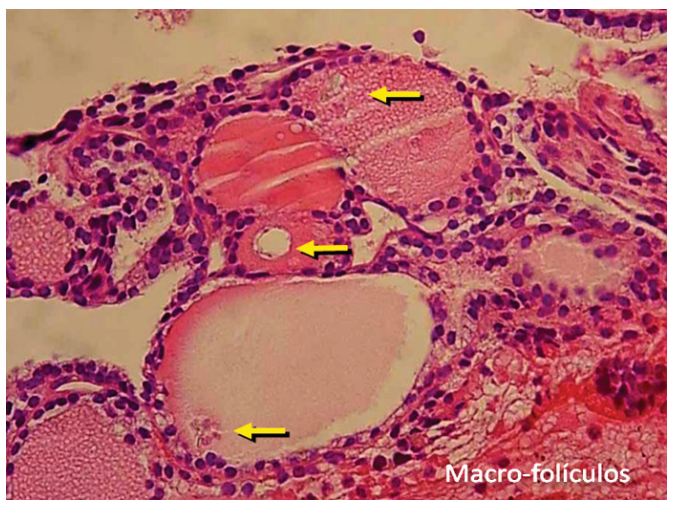

Figura 7. Muestra de PAAF con coágulo. El fragmento tisular permite un estudio histológico: nódulo coloideo hiperplástico con macrofolículos repletos de coloide, revestidos por epitelio aplanado con núcleos de tamaño uniforme. Detritus de cristales (oxalato de calcio y colesterol) (flechas) que explican los spots hiperecogénicos en ecografía.
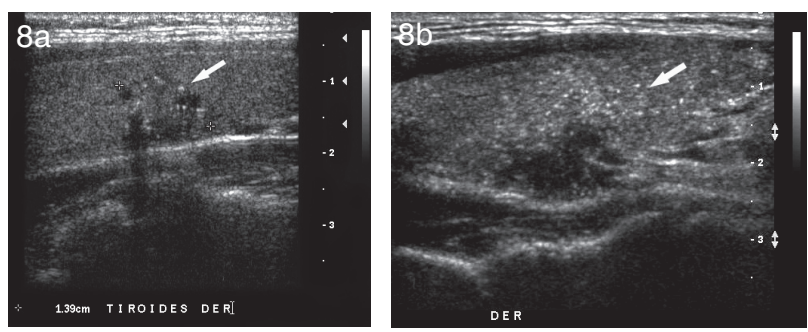

Figura $8(\mathbf{a}, \boldsymbol{b})$. No se debe confundir los spots hiperecogénicos que indican la presencia de material coloide con los psammomas que caracterizan los cánceres tiroideos. Estos se encuentran en el parénquima sólido hipo o isoecogénico (flechas).
Pequeños nódulos coloideos mixtos pueden presentarse como un quiste con nódulo mural hipervascularizado (Figura 9 a, b). Esta imagen se conoce en anatomía patológica como "Sanderson's polster"(7) y corresponde a la protrusión de pequeños folículos hacia el lumen de un folículo muy dilatado (Figura 9 c). No requieren punción.

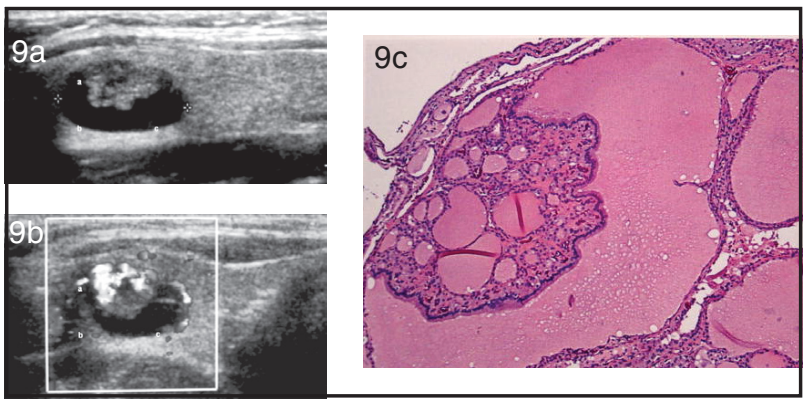

Figura $9(\boldsymbol{a}, \boldsymbol{b}, \boldsymbol{c})$. Pequeño nódulo mixto, habitualmente vascularizado, se presenta como un quiste con nódulo mural (a $y$ b). No se debe confundir con lesión papilomatosa, es un simple nódulo coloideo. No requiere punción. Los patólogos conocen esta imagen como "Sanderson's polster» correspondiente a la protrusión de pequeños folículos hacia el lumen de un folículo muy dilatado (c).

En nódulos coloideos principalmente quísticos de mayor tamaño, se entremezclan áreas líquidas y sólidas dando lugar a formaciones muy exóticas con mamelones, tabiques gruesos y paredes engrosadas en forma irregular. Al Doppler color se aprecia un marcado aumento de la vascularización (Figura 10a). Hay que hacer hincapié en el hecho de que en el contexto de nódulos coloideos todos estos hallazgos inquietantes no significan necesariamente malignidad; aquí se trata de un frágil tejido de granulación de tipo reactivo, inflamatorio (Figura 10b), por lo que estos nódulos tampoco necesitan punción diagnóstica.
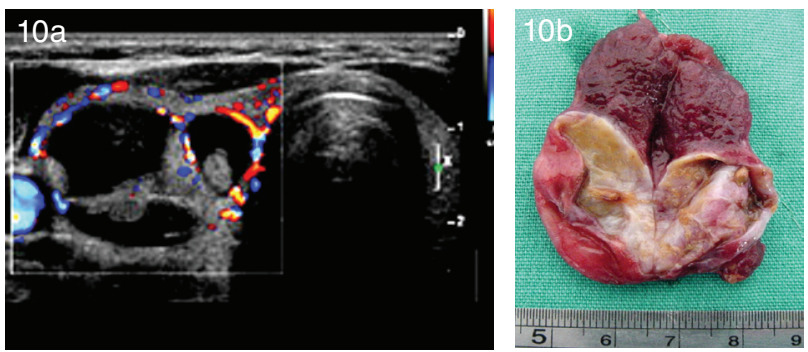

Figura 10 (a, b). Paredes engrosadas, tabiques, imágenes vegetantes endoquísticas e hipervascularización son los signos ecográficos que caracterizan un típico nódulo coloideo mixto (a). Estos hallazgos inquietantes no significan necesariamente malignidad; aquí se trata de un frágil tejido de granulación, de tipo reactivo, inflamatorio (b). 
En este estudio se evidenció que la mayoría $(67,2 \%)$ de los nódulos coloideos aparecen en US con patrones coloideos típicos (tipo $1=0,8 \%$, tipo $2=1,6 \%$ y tipo $3=64,8 \%$ ), mientras un tercio de ellos $(32,8 \%)$, semeja nódulos neoplásicos $(27,3 \%)$ e incluso malignos $(5,5 \%)$.

También se demostró que los nódulos con patrones coloideos tipos 1, 2 y 3 tienen una muy baja $(1,5 \%)$ asociación con cáncer (Tabla II).

Es interesante analizar los falsos negativos en US, vale decir los 7 casos con resultado maligno en la PAAF entre los 478 nódulos de patrón coloideo tipo 3 (Tabla II). Se trata de una forma rara de cáncer papilar, el cáncer papilar intraquístico. Según los datos de la literatura, un nódulo mixto aparentemente coloideo se convierte en dudoso o sospechoso si es de gran tamaño, mayor a 3-4 $\mathrm{cm}^{(8,9)}$, en hombres ${ }^{(8)}$, en presencia de una masa pediculada intraquística ${ }^{(10)}$, por la existencia de calcificaciones en su porción sólida ${ }^{(11)}$ y frente a un crecimiento rápido. Según nuestra experiencia, el aspecto esférico y la ausencia de spots hiperecogénicos son los elementos ultrasonográficos más importantes que hacen dudar de un nódulo coloideo de tipo 3 (Figura 11). De todas formas, 7 cánceres papilares en 478 nódulos puncionados, representan menos de $2 \%$, por lo que-razonablemente-se puede recomendar su control ultrasonográfico.

En nuestra serie existe un fuerte sesgo por una rigurosa selección ultrasonográfica previa a la punción. El $36 \%$ de las punciones no resulta benigna en la PAAF: neoplasia folicular (14\%) y cáncer $(22 \%)$ (Figura 6). No obstante, se podría mejorar la actual relación entre punción benigna $\mathrm{v} / \mathrm{s}$ no benigna de 1,7:1 al evitar la punción de los nódulos coloideos típicos.

En nuestra ficha de PAAF, existe un ítem "puncionaría / no puncionaría" para el radiólogo. Si sólo hubiéramos puncionado los nódulos estimados necesarios por los radiólogos, de los 1.188 procedimientos realizados hubiéramos obviado 400 . Entre ellos hubo $362(90,5 \%)$ benignos, $34(8,5 \%)$ Neoplasias Foliculares y sólo 4 (1\%) malignos.
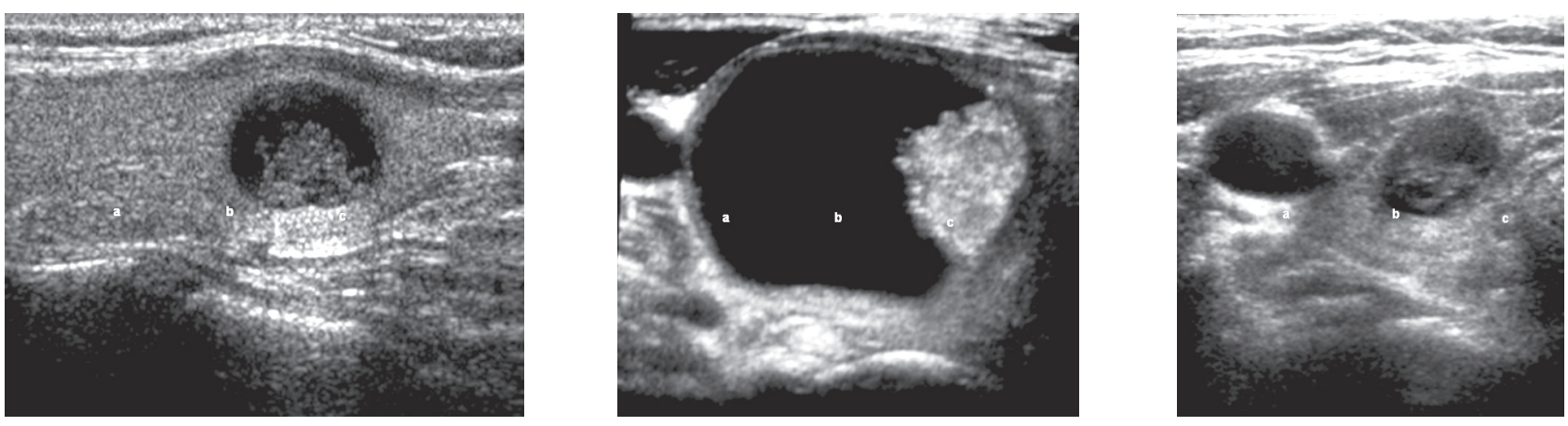

Figura $11(a, b, c)$. Tres de los 7 casos de falsos negativos en US (cánceres papilares quísticos), que parecen nódulos coloideos mixtos tipo 3. Según nuestra experiencia, fuera del crecimiento rápido y presencia de calcificaciones en la porción sólida del nódulo, el aspecto esférico y la ausencia de spots hiperecogénicos son los elementos ecográficos más importantes que hacen dudar de un nódulo coloideo.

Tabla II. Distribución en 5 categorías de los 1.188 nódulos puncionados bajo ecografía y estudiados histológicamente.

\section{Patrones pre-definidos Número de nódulos Número de cánceres $\%$ de malignidad}

$\begin{array}{lrrr}\text { Patrón coloideo Tipo 1 } & 5 & 0 & 0 \\ \text { Patrón coloideo Tipo 2 } & 10 & 0 & 0 \\ \text { Patrón coloideo Tipo 3 } & 478 & 7 & 1,5 \\ \text { Patrón neoplásico } & 521 & 53 & 10,2 \\ \text { Patrón maligno } & 174 & 113 & 64,9 \\ & & & 14,6\end{array}$




\section{Conclusiones}

Los nódulos coloideos representan las lesiones más frecuentes de la glándula tiroides. Pueden simular todo tipo de nódulos, incluyendo neoplasias foliculares y cánceres. Sin embargo, el $67 \%$ de ellos posee un aspecto ultrasonográfico característico, descrito como patrones coloideos tipo 1, 2 y 3 . Estos sub-grupos raramente se asocian con cáncer (en menos de $2 \%$ de los casos de nuestra serie), por lo que se recomienda su seguimiento ultrasonográfico. Al reconocerlos, se puede disminuir en forma significativa la tasa de punciones diagnósticas innecesarias.

\section{Bibliografía}

1. Tan GH, Gharib H. Thyroid incidentalomas: Management approaches to nonpalpable nodules discovered incidentally on thyroid imaging. Ann Intern Med 1997; 126: 226-231.

2. Hegedus L. The thyroid nodule. N Engl J Med 2004; 351: 1764-1771.

3. Domínguez M, Franco C, Contreras L et al. Punción por aguja fina del tiroides. Análisis de los resultados obtenidos usando un nuevo método con estudio histológico de la muestra. Rev Med Chil 1995; 123(8):
982-990.

4. Hall TL, Lagfield LJ, Philippe A et al. Source of diagnostic error in fine needle aspiration of the thyroid. Cancer 1989; 63(4): 718-25.

5. X Curso de Radiología y I Simposio Multidisciplinario de Tiroides: Imágenes, clínica y anatomía patológica. Libro de Resúmenes julio de 2006, Clínica Alemana de Santiago.

6. Ahuja A, Chick W, King W, Metreweli C. Clinical significance of the comet-tail artifact in thyroid ultrasound. J Clin Ultrasound. 1996; 24(3): 129-33.

7. Lloyd Ricardo V. Atlas of Nontumor Pathology, Endocrine Diseases, First Series, Fascicle 1, AFIP, ARP, 2002.

8. Choi KU, Kim JY, Park DY, Lee CH, Sol MY, Han KT et al. Recommendations for the management of cystic thyroid nodules. ANZ J Surg. 2005; 75(7): 537-41.

9. Abbas G, Heller KS, Khoynezhand A, Dubner S, Sznyter $\mathrm{LA}$. The incidence of carcinoma in cytologically benign thyroid cysts. Surgery. 2001; 130(6): 1.035-8.

10. Hiromura T, Nojima T, Morita Y, Choji K, Nakada K, Tsukamoto $\mathrm{E}$ et al. Cystic papillary carcinoma of the thyroid-sonographic-pathologic correlation Nippon Igaku Hoshasen Gakkai Zasshi. 1990; 50(1): 40-7.

11. Hatabu H, Kasagi K, Yamamoto K, lida Y, Misaki T, Hidaka A et al. Cystic papillary carcinoma of the thyroid gland: a new sonographic sign. Clin Radiol 1991; 43(2): 121-4. 